\title{
Asymmetries and Shortages of the Network Neutrality Principle
}

\author{
What could neutrality achieve?
}

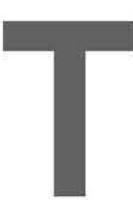

HE DEBATE ON network neutrality has reached sufficient notoriety to eliminate the need for detailed explanation. A simple definition will suffice: "network neutrality" is understood as the principle by which the owners of broadband networks would not be allowed to establish any type of discrimination or preference over the traffic transmitted through them.

What is indeed interesting to remember is the origin of the debate. In February 2002, the U.S. the Federal Communications Commission (FCC), launched a proposal considering DSL connections as an "information service" and, thus, not subject to access requirements telephone companies must fulfill. The following month, the FCC launched a similar draft for cable networks and requested comments on what the regulatory regime that would finally prevail should look like. The comments received by the FCC, particularly those of the High Tech Broadband Coalition (HTBC) Group, which integrates different associations and partnerships of the ICT industry, represent the starting point of the subsequent controversy. ${ }^{9}$

We recall the beginning of the controversy because, since then and perhaps as an inheritance of this beginning, it has been restricted to fixed broadband networks. Indeed, academic papers, political opinions and media

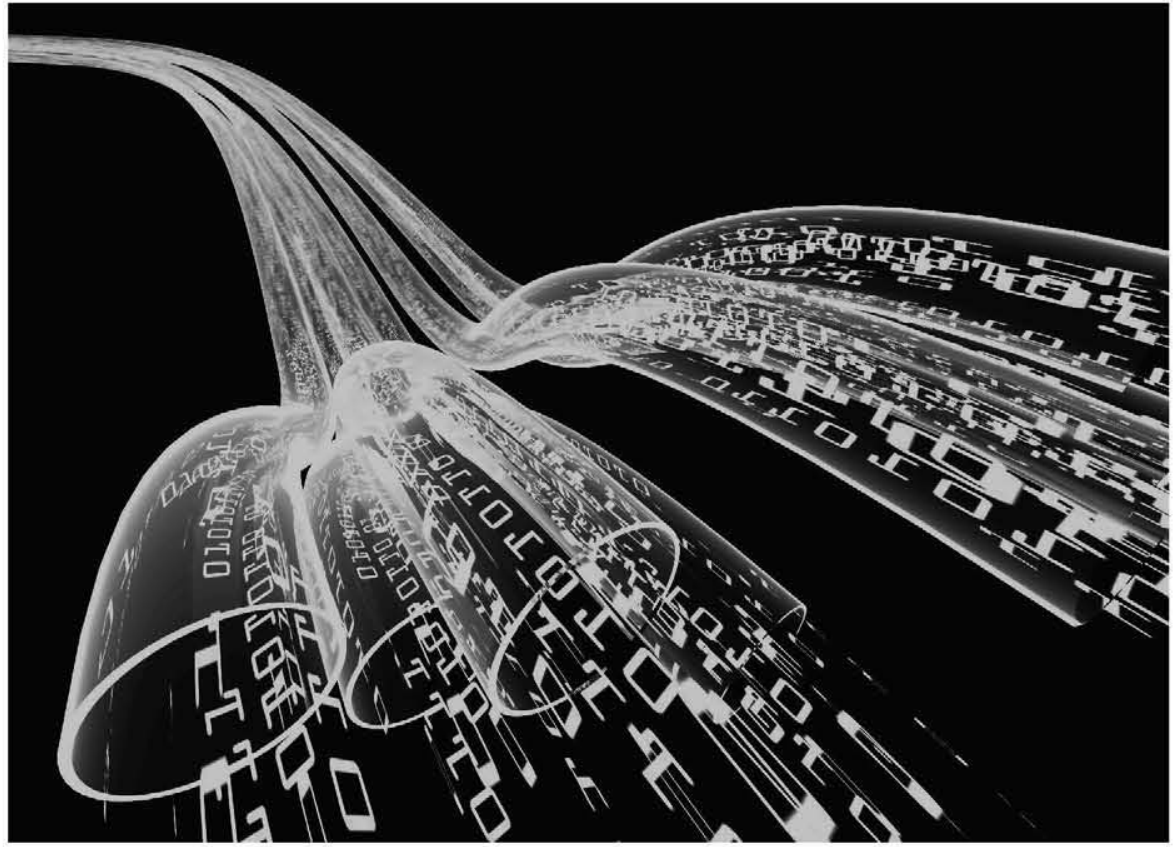

comments have appeared in favor of or against network neutrality but have always shared one issue: the opinions provided continue to limit the fight to the scope of traditional networks (telephone or cable). Take as the most prominent example the two articles recently published by Communications on the topic. Van Schewick and Farber's Point/Counterpoint explicitly played on the landline carriers' court. ${ }^{6}$ In his less prescriptive, more descriptive (regulatory) Viewpoint, Larouche uses a broader term (ISPs) but takes a similar approach. ${ }^{3}$
It is not our intention to provide new arguments underlining the virtues of the supporting or opposing positions. The matter we would like to stress is the narrow-mindedness of the approach that is adopted repeatedly. It must be remembered that the defenders of network neutrality base their arguments on the need to avoid closing the door to any innovation: the Internet would simply be a platform necessary for the competition between application developers (see, for example, Weinstein ${ }^{7}$ ). With this idea in mind, there are three axes 
toward which the debate could, or should, extend.

First, it is interesting to recall the opinion of Zittrain, for whom "Internet is better conceptualized as a generative grid that includes both PCs and networks rather than as an open network indifferent to the configuration of its endpoints." ${ }^{10}$ This way, what occurs in the pipes would be only a part of the problem and what he defines as "PC openness" could be set out. In fact, this is the path where the more theoretical journey has taken place, thanks basically to the work of open source software supporters. However, it is surprising that connections with network neutrality have not been explored in greater depth. And this is not just about PCs. As other electronic devices (consider mobile handhelds, and more specifically, smartphones) win the favor of consumers, so does their role as intermediary (always neutral?) between applications or content creators and possible clients.

Second, quite outstanding is the fact that, until the FCC's Notice of Proposed Rulemaking, released oct. 22,2009 , and with a few significant exceptions (such as Frieden ${ }^{1}, \mathrm{Wu}^{8}$ ), no one had considered wireless connections in their analyses. It can be said that, although not specifically stated, a certain degree of consensus for "naturally" extending the current arguments to Wi-Fi or WiMax networks has probably existed. But what about mobile operators? If there is a service where network neutrality has been really breached, it is the data access service provided by mobile operators. The extreme discrimination model ("walled garden") is still used by operators throughout the world. Walled gardens have been accepted as another of the possible business strategies of companies operating in the sector, and almost no one has torn their hair out. Without going to the extreme represented by walled gardens, are there any circumstances, as the FCC asks, in which it could be reasonable for a wireless network to block video, VoIP, or peer-to-peer applications?

Last, the focus must be targeted toward some of the applications that have become the de facto door for accessing the Internet and that can be considered as instrumental as the

\section{What is clear is that in a convergent scenario the coexistence of different regulatory criteria does not seem fair:}

network itself. It must be considered that for every business project where it is vital that the network owner does not discriminate the traffic generated by the application, there are probably another 100 whose concern is limited to the order in which they appear in a specific portal or search engine. And here one can find a clear asymmetry between what is supported "downward" and what actually happens "upstairs." Naturally, search engines, portals, and aggregators of diverse content or directories quickly joined the defenders of network neutrality.... fact that does not prevent them from prioritizing certain customers: those with which they have a "special relationship" or, simply, those that pay. That is exactly the opposite of what these same companies demand from network operators. Let us clarify that discrimination is not always arbitrary or unfair. In particular, search engines must follow some regulatory guidelines ${ }^{2}$ but still discrimination is possible. Along the same line, Pasquale ${ }^{5}$ or Odlyzko ${ }^{4}$ have already discussed the parallelism between the basic principles of transparency that should similarly inform carriage and search regulation.

Note that the use of the condition in the title of this column means the authors do not call for the imposition of a "universal" neutrality affecting networks, equipment, software, and applications (could we call it gatekeeper neutrality?). Without engaging in such a discussion, what we do assert is that the analysis, in its current dimension, does not go far enough.

Neutrality has other facets, certainly. Another neutrality, often presented as a cornerstone for correct regula- tion-technological neutrality-already demands an initial reconsideration of the reasoning. But even beyond that, in a convergent industry where agents from "different worlds" often fight to conquer the same links in the value chain (integrating as many activities as possible for a tighter control of the value network), the rules of the game should be equal for everyone. While most of these agents are judged ex post, and their activity is limited only when it harms competition or hampers the development of the markets, others have to comply with stringent ex ante regulations. This does not necessarily imply that the antitrust-oriented approach should be extended to any party. On the contrary, a general forward-looking regulatory model that would guarantee certain rights and abilities (such as privacy and interoperability) would probably be needed.

In any case, what is clear is that in a convergent scenario the coexistence of different regulatory criteria does not seem fair. And one must not forget that convergence, the same convergence that never seems to arrive, cannot be slowed down.

\section{References \\ 1. Frieden, $R$. The costs and benefits of separating wireless telephone service from handset sales and imposing network neutrality obligations. In Proceedings of the First ITU-T Kaleidoscope Academic Conference Innovations in NGN: Future Network and Services (Geneva, May 12-13, 2008), 273-278. \\ 2. Gasser, U. Regulating search engines: Taking stock and looking ahead. Yole Joumal of Law \& Technology 8 (2006), 202-234. \\ 3. Larouche, P. The network neutrality debate hits Europe. Commun. ACM 52, 5 (May 2009), 22-24. \\ 4. Odlyzko, A. Network neutrality, search neutrality, and the never-ending conflict between efficiency and faimess in markets. Review of Network Economics 8, 1 (2009), 40-60. \\ 5. Pasquale, F. Internet nondiscrimination principles: Commercial ethics for carriers and search engines. University of Chicago L egal Forum 2008 (2008), 263-300. \\ 6. Van Schewick, B. and Farber, D. Network neutrality nuances. Commun. ACM 52, 2 (Feb. 2009), 31-37. \\ 7. Weinstein, L. Ma Bell's revenge: The battle for network neutrality. Commun. ACM 50, 1 (Jan. 2007), 128. \\ 8. Wu, T. Wireless Carterfone. International Joumal of Communications 1 (2007), 389-426. \\ 9. Yoo, C. Network neutrality and the economics of congestion. Georgetown Law Journal 94, 6 (2006). 1847-1908. \\ 10. Zittrain. J.L. The generative Internet. Harvard Law Review 119, 7 (2006), 1974-2040.}

José Luis Gómez-Barroso (jlgomez@cee.uned.es) is an associate professor in the Department of Applied Economics and Economic History at the National University of Distance Education, Spain.

Claudio Feijóo (cfeijoo(đcedint.upm.es) is a professor at the Universidad Politécnica de Madrid, Spain, and a Senior Member of ACM.

Copyright held by author. 